\title{
Journal of Psychophopharmacology
}

Lamotrigine treatment of aggression in female borderline patients, Part II: an 18-month follow-up

P. Leiberich, MK Nickel, K. Tritt and F Pedrosa Gil

J Psychopharmacol 2008 22: 805 originally published online 28 February 2008

DOI: $10.1177 / 0269881107084004$

The online version of this article can be found at:

http://jop.sagepub.com/content/22/7/805

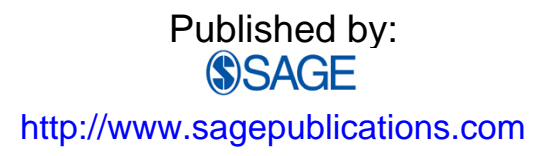

On behalf of:

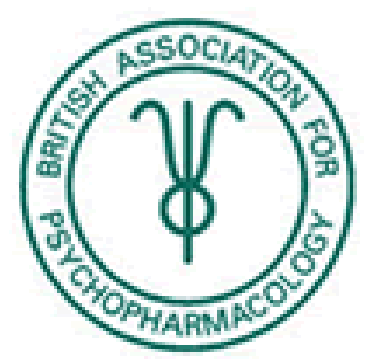

British Association for Psychopharmacology

Additional services and information for Journal of Psychopharmacology can be found at:

Email Alerts: http://jop.sagepub.com/cgi/alerts

Subscriptions: http://jop.sagepub.com/subscriptions

Reprints: http://www.sagepub.com/journalsReprints.nav

Permissions: http://www.sagepub.com/journalsPermissions.nav

Citations: http://jop.sagepub.com/content/22/7/805.refs.html

>> Version of Record - Aug 27, 2008

OnlineFirst Version of Record - Feb 28, 2008

What is This? 


\title{
Lamotrigine treatment of aggression in female borderline patients, Part II: an 18-month follow-up
}

Journal of Psychopharmacology 22(7) (2008) 805-808 (C) 2008 British Association for Psychopharmacology ISSN 0269-8811 SAGE Publications Los Angeles, London, New Delhi and Singapore $10.1177 / 0269881107084004$

\author{
P Leiberich Inntalklink, Simbach am Inn, Germany. \\ MK Nickel Clinic for Psychosomatic Medicine and Psychotherapy, Medical University of Graz, Bad Aussee, \\ Austrian University Clinic for Psychiatry 1, PMU, Salzburg, Austria. \\ K Tritt Department of Psychosomatic Medicine, University Clinic, Regensburg, Germany. \\ F Pedrosa Gil Psychosomatic Outpatient Clinic, University Medicine Clinic, LMU, Munich, Germany.
}

\begin{abstract}
Borderline patients often display pathological aggression. We previously tested lamotrigine, an anti-convulsant, in therapy for aggression in women with borderline personality disorder (BPD) (J Psychopharmacol 2005; 19: 287-291), and found significant changes on most scales of the State-Trait Anger Expression Inventory (STAXI) after eight weeks. To assess the longerterm efficacy of lamotrigine in therapy for aggression in women with BPD, this 18-month follow-up observation was carried out, in which patients (treated with lamotrigine: $n=18$; former

placebo group: $n=9$ ) were tested every six months. According to the
\end{abstract}

intent-to-treat principle, significant changes on all scales of the STAXI were observed in the lamotrigine-treated subjects. All subjects tolerated lamotrigine relatively well. Lamotrigine appears to be an effective and relatively safe agent in the longer-term treatment of aggression in women with BPD.

\section{Keywords}

borderline personality disorder, aggression, lamotrigine

\section{Introduction}

The treatment of symptoms in borderline personality disorder (BPD), including aggression, has been studied intensively (Zanarini, 2004). The efficacy of selective serotonin reuptake inhibitors, atypical neuroleptics and with the exception of valproate and carbamazepine, anti-epileptic drugs in the treatment of pathological aggression remains to be established (Fava, 1997; Azouvi et al., 1999; Tariot et al., 1998; Nickel et al., 2004; Nickel et al., 2005; Loew et al., 2006; Nickel et al., 2006). Effective pharmacological interventions with lamotrigine, an anti-convulsant, in borderline patients have also been reported (Pinto and Akiskal, 1998; Preston et al., 2004); however, until now, only one controlled trial is known, which employed this medication for patients with BPD (Tritt et al., 2005). That study was carried out in a double-blind and placebo-controlled design with women with BPD (Tritt et al., 2005), and after eight weeks' treatment with a daily dose of up to $200 \mathrm{mg}$ lamotrigine, significant changes on most scales of the State-Trait Anger Expression Inventory (STAXI) (Schwenkmezger et al., 1992) were observed. In the present, follow-up observation of patients who participated in the above-mentioned study (Tritt et al., 2005), the longer-term influence of lamotrigine on anger symptoms in women with BPD was investigated.

\section{Methods}

The procedure for recruitment of the study sample has already been described in detail in our first report (Tritt et al., 2005).

The exclusion criteria for the follow-up observation were schizophrenia, current use of psychotropic medication in the previous placebo group (PG), termination of lamotrigine in the lamotrigine group (LG), as well as current psychotherapy, current suicidal ideation, severe somatic illness or abuse of drugs or alcohol in either group. Potential subjects were also excluded if they were pregnant, planning to be, or not using contraception. During the course of the follow-up study, additional subjects were excluded who missed more than one evaluation.

The subjects were invited to participate in face-to-face interviews. The possible side effects were fully explained once again. Primary 
outcome measures were changes in the STAXI (Schwenkmezger et al., 1992), described in detail elsewhere (Tritt et al., 2005).

The necessary sample size calculation and the randomization were described in detail, in our report of the the first study, in which female patients were treated for eight weeks in 2004 with a daily dose of up to $200 \mathrm{mg}$ lamotrigine (LG: $n=18$ ) or with a placebo (PG: $n=9$ ), and tested with STAXI every week (Tritt et al., 2005). Following the final testing, the blind was broken.

After completion of the above-mentioned study, an 18-month follow-up was carried out, in which the patients (LG: $n=18$; former [Ex-PG]: $n=9$ ) were tested every six months. The patients in the LG took continued taking $200 \mathrm{mg}$ lamotrigine daily. The Ex-PG took neither lamotrigine nor placebo. During the course of the trial, the intermediate results were not analysed. After eighteen months, both groups were tested for the last time and physically examined. Ten subjects dropped out; of these, two were from the PG and one from the LG during the placebocontrolled study (Tritt et al., 2005), and seven dropped out during the follow-up: two who missed more than one evaluation (one from the LG), one from the LG who changed residence, one from the LG due to termination of lamotrigine, and three from the Ex-PG due to initiation of therapy with lamotrigine or another psychopharmica. The test-questionnaires were filled out by the patients both independently and anonymously. Our staff checked the data for completeness. The study was concluded according to plan.

\section{Data analysis}

We used the statistical program SPSS, Version 12 (SPSS Inc. Chicago, Illinois, USA) to analyse the data according to the intend-to-treat principle. Data are presented as means and standard deviations.

A two-factor repeated measure analysis of variance was performed. The treatment condition was defined as the betweensubject factor, and the measurements in time as the within-subject factor. When the assumptions for performing the repeated measure analysis were not given, the results were adjusted using the Greenhouse-Geisser Epsilon (Stevens, 1992). To assess whether there were differences at the initial and final points, multiple comparisons were performed using contrasts for each treatment condition. The significance levels were corrected using the Bonferroni correction. Changes in the dichotomy parameters, employment and partnership were analysed by means of the binominal test (Dufner et al., 1992).

\section{Source of funding and ethical considerations}

The study was planned and conducted in accordance with the Declaration of Helsinki and ethical laws pertaining to the medical professions and its design approved by the clinic's 'Ethikkomission' (the German equivalent of the Committee on Human Subjects). All subjects gave written informed consent. The study was conducted independent of any institutional influence and was not funded. There were no conflicts of interest.

\section{Results}

The detailed medical and social data from the patients of both groups were described and compared with each other in the previous publication (Tritt et al., 2005).

Table 1 summarizes the changes in both groups over the course of the entire study. The LG experienced a significantly greater changes than the placebo/Ex-PG on all STAXI scales.

No serious side effects were observed. In isolated cases, relatively mild rash, dizziness, headache and nausea were reported. Two subjects from the Ex-PG and one from the LG engaged in self-mutilation, and one from the Ex-PG attempted suicide during the study. In addition, weight loss was observed after eighteen months treatment. In the LG, weight loss was no more significant than in the (PG) [LG: starting weight $\mathrm{MV}=78.6 \pm 10.1 \mathrm{~kg}$, weight after 18 months $\mathrm{MV}=77.8 \pm 11.9 \mathrm{~kg}$; Ex-PG: starting weight $\mathrm{MV}=77.3 \pm 11.4 \mathrm{~kg}, \mathrm{BMI}=26.8$, weight after 18 months $\mathrm{MV}=78.5 \pm 13.7 \mathrm{~kg} ; \mathrm{p}(\mathrm{IE})=0.65, \mathrm{p}(\mathrm{FE})=0.01$, $P($ group $\times$ time effect $)=0.43, P($ group effect $)=0.31]$.

\section{Discussion}

During the entire observation period, there was a significantly greater change on all STAXI scales (Schwenkmezger et al., 1992) in the lamotrigine-treated group that in the placebo/ex-PG. Specifically, lamotrigine was more effective in treating the aggression component of borderline psychopathology, which corroborates the previous report (Tritt et al., 2005). Among our patients, lamotrigine appeared to influence the intensity of the perceived feeling of anger as well as the threshold for perceiving it. The way aggression was processed intra-psychologically was possibly also influenced, and in the final analysis even the socially desirable control of anger as well.

The most common side effects of lamotrigine are headache, nausea, dizziness, infection, dry mouth, diarrhea, somnolence, ataxia, tremor, insomnia, rash and withdrawal (Messenheimer et al., 1998). All our patients tolerated it well or very well; unpleasant symptoms were reported only in isolated cases. Moderate weight loss was observed and was usually regarded as beneficial. In the literature, both moderate weight loss and mood stabilization have been attributed to lamotrigine (Calabrese, 2003). However, our study could only demonstrate that weight remained constant with lamotrigine.

The results of this trial are consistent with those of earlier studies which found that anti-convulsant medications are effective in the treatment of pathologic aggression (Fava, 1997; Azouvi et al., 1999; Tariot et al., 1998). Rizvi (2002) and Pinto and Akiskal (1998) reported decreased symptoms of aggression in borderline patients undergoing lamotrigine therapy.

One of the limitations was that the sample size was relatively small, and both the blind and placebo medication were discontinued. In addition, the relatively high dropout rate limits the extent to which the results can be generalized. The study focused on only one dimension of BPD in borderline women, namely, aggressiveimpulsivity. The effects of lamotrigine on other dimensions of 


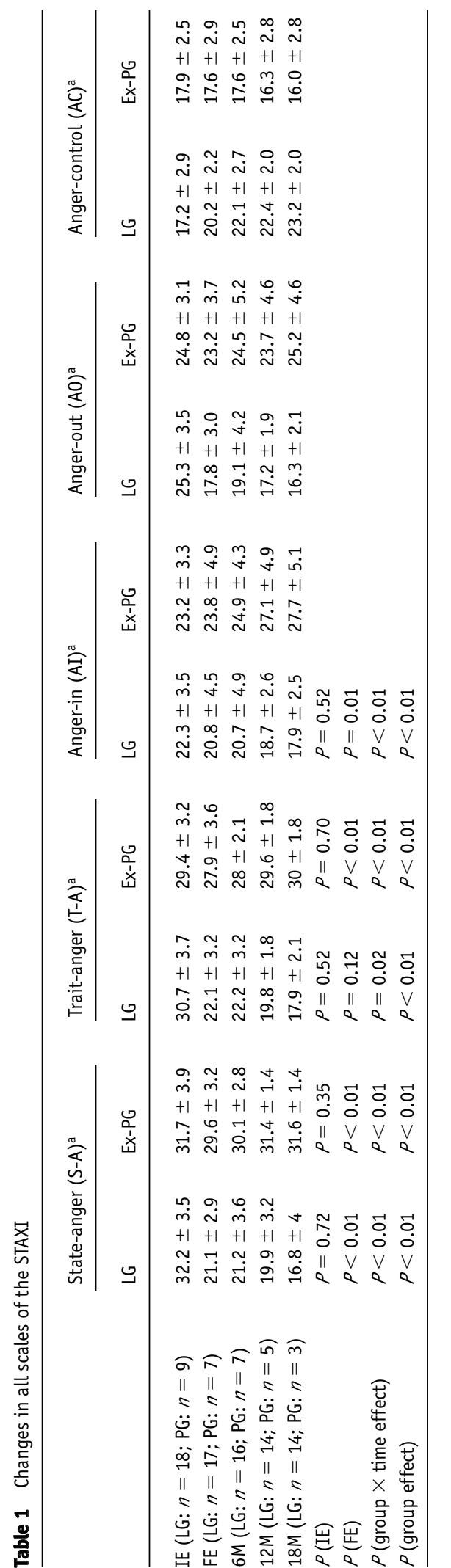

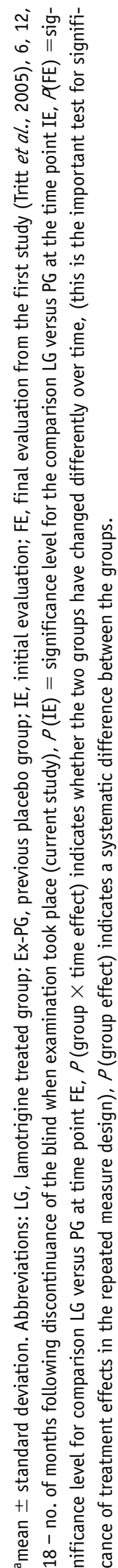

BPD, such affective dysregulation, cognitive perceptual impairment and disturbed relationships, were not evaluated. Additional placebo-controlled trials of longer duration are needed to see if these results can be replicated.

Following a longer period of observation, lamotrigine appears to be a safe and effective agent for improving aggression in borderline women (Tritt et al., 2005), and the treatment effect ascertained in a placebo-controlled study (Tritt et al., 2005) could be corroborated in this subsequent observational study. The results of this trial corroborates other reports in which anti-convulsants (Tariot et al., 1998, Nickel et al., 2004; Nickel et al., 2005; Tritt et al., 2005) were found to be effective in the treatment of pathologic aggression.

\section{Acknowledgement}

The authors are grateful to Ann Marie Ackermann, JD for translating and editing this article.

\section{References}

Azouvi P, Jokic C, Attal N, Denys P, Markabi S, Bussel B (1999) Carbamazepine in agitation and aggressive behaviour following severe closed-head injury: results of an open trial. Brain Inj 13: $797-804$

Calabrese J R (2003) 16th Congress of European College of Neuropsychopharmacology [ECPN). Prag 20-24 September

Dufner J, Jensen U, Schumacher E (1992) Statistik mit SAS. Teubner, Stuttgart

Fava M (1997) Psychopharmacologic treatment of pathologic aggression. Psychiatry Clin North Am 20: 427-431

Loew T, Nickel M, Kaplan P, Nickel C, Muehlbacher M, Kettler C, Lahmann C, Buschmann W, Tritt K, Leiberich P, Rother W, Egger C (2006) Topiramate treatment of women with borderline personality disorder: a double-blind, placebo-controlled study. J Clin Psychopharmacol 26: 61-66

Messenheimer J, Mullens E L, Giorgi L, Young F (1998) Safety review of adult clinical trial experience with lamotrigine. Drug Saf 18 : 281-296

Nickel M K, Nickel C, Mitterlehner F O, Tritt K, Lahmann C, Leiberich P K, Rother W, Loew T (2004) Topiramate treatment of aggression in female borderline personality disorder patients: a double blind, placebo-controlled study. J Clin Psychiatry 65: $1515-1519$

Nickel M, Nickel C, Kaplan P, Lahmann C, Muehlbacher M, Tritt K, Rother W, Loew T (2005) Treatment of aggression with topiramate in male borderline patients: a double-blind, placebo-controlled study. Biol Psychiatry 57: 495-499

Nickel M, Muehlbacher M, Nickel C, Kettler C, Pedrosa Gil F, Bachler E, Buschmann W, Rother N, Fartacek R, Egger C, Anvar J, Rother W, Loew T, Kaplan P (2006) Aripiprazole in treatment of borderline patients: a double-blind, placebo-controlled study. Am J Psychiatry 163: 833-838

Pinto O C, Akiskal H S (1998) Lamotrigine as a promising approach to borderline personality: an open case series without concurrent DSM-IV major mood disorder. J Affect Disord 51: 333-343

Preston G A, Marchant B K, Reimherr F W, Strong R E, Hedges D W (2004) Borderline personality disorder in patients with bipolar disorder and response to lamotrigine. J Affect Disord 79: 297-303

Rizvi S T (2002) Lamotrigine and borderline personality disorder. J Child Adol Psychopharmacol 12: 365-366 
Schwenkmezger P, Hodapp V, Spielberger C D (1992) Das StateTrait-Aergerausdrucks-Inventar. Huber, Bern, Goettingen, Toronto

Stevens J (1992) Applied multivariate statistics for the social sciences. Erlbaum, New Jersey

Tariot P N, Erb R, Podgorski C A, Cox C, Patel S, Jakimovich L (1998)

Efficacy and tolerability of carbamazepine for agitation and aggression in dementia. Am J Psychiatry 155: 54-61
Tritt K, Nickel C, Mitterlehner F, Tritt K, Lahmann C, Leiberich P, Rother W, Loew T, Nickel M (2005) Lamotrigine treatment of aggression in female Borderline Personality Disorder Patients: A double-blind, placebo-controlled study. J Psychopharmacol 19: 287-291

Zanarini M (2004) Update on pharmacotherapy of borderline personality disorder. Curr Psychiatry Rep 6: 66-70 